This is an electronic reprint of the original article. This reprint may differ from the original in pagination and typographic detail.

Author(s): Heikkinen, Juho; Isomöttönen, Ville

Title: Learning mechanisms in multidisciplinary teamwork with real customers and openended problems

Year: $\quad 2015$

Version:

Please cite the original version:

Heikkinen, J., \& Isomöttönen, V. (2015). Learning mechanisms in multidisciplinary teamwork with real customers and open-ended problems. European Journal of Engineering Education, 40(6), 653-670.

https://doi.org/10.1080/03043797.2014.1001818

All material supplied via JYX is protected by copyright and other intellectual property rights, and duplication or sale of all or part of any of the repository collections is not permitted, except that material may be duplicated by you for your research use or educational purposes in electronic or print form. You must obtain permission for any other use. Electronic or print copies may not be offered, whether for sale or otherwise to anyone who is not an authorised user. 
To appear in the European Journal of Engineering Education

Vol. 00, No. 00, Month 20XX, 1-19

\title{
Learning Mechanisms in Multidisciplinary Teamwork with Real Customers and Open-ended Problems
}

\author{
Juho Heikkinen ${ }^{\mathrm{ab} *}$ and Ville Isomöttönen ${ }^{\mathrm{b}}$ \\ ${ }^{a}$ Agora Center, University of Jyväskylä, Finland; ${ }^{b}$ Department of Mathematical Information \\ Technology, University of Jyväskylä, Finland
}

(v3.1 released October 2013)

\begin{abstract}
Recently, there has been a trend towards adding a multidisciplinary or multicultural element to traditional monodisciplinary project courses in computing and engineering. In this article, we examine the implications of multidisciplinarity for students' learning experiences during a one-semester project course for real customers. We use a qualitative research approach and base our analysis on students' learning reports on three instances of a project course titled Multidisciplinary working life project. The main contribution of this article is the unified theoretical picture of the learning mechanisms stemming from multidisciplinarity. Our main conclusions are that (1) students generally have a positive view of multidisciplinarity; (2) multidisciplinary teams enable students to better identify their own expertise, which leads to increased occupational identity; and (3) learning experiences are not fixed, as team spirit and student attitude play an important role in how students react to challenging situations arising from introduction of the multidisciplinarity.
\end{abstract}

Keywords: project-based learning, multidisciplinary education

\section{Introduction}

Computing and engineering education has a long history of using projects as a teaching method. In fact, even the first curriculum in software engineering included a "true-to-life" programming project, and since then project courses have constituted a fixed part of software engineering education (Tomayko 1998). In the present day, project-based learning is implemented in these disciplines through a range of course models and arrangements (Fincher, Petre, and Clark 2001; Clear et al. 2001). One of the recent trends is adding a multicultural or international element to the traditional project courses (e.g. Pears and Daniels 2010). Another trend is that courses are organized in collaboration between two or three departments or faculties, thus bringing a multidisciplinary element to the project work (e.g. Burnell, Priest, and Durrett 2003). Both of these trends correspond with the fact that in today's working life one often has to work in multicultural (Last et al. 2000) or multidisciplinary environments (Kruck and Teer 2009).

This article reports on a multidisciplinary working life course offered at the University of Jyväskylä, Finland. Our research interest is in the implications that the multidisciplinary character of the course has for students' course work. This research interest emerged through commencing an inductive grounded theory analysis (Glaser and Strauss 1967; Glaser 1978) on the learning reports that students are required to prepare at the

*Corresponding author. Email: juho.e.heikkinen@jyu.fi 
end of their projects. We find this theory development-oriented research approach welcome, as the project education field is often studied in the form of course descriptions (Helle, Tynjälä, and Olkinuora 2006). Another unique feature of the present research is that the course under study is targeted at students in all faculties of the University, whereas the multidisciplinary project courses discussed in the literature are often centered on a couple of core disciplines (e.g. Mosiman and Hiemcke 2000; Hirsch et al. 2001; Burnell, Priest, and Durrett 2003; Kruck and Teer 2009). This aforementioned approach used in our project course enables a broader scope of project topics and student team compositions. We base our study on qualitative data collected during three instances of the course where a total of 88 students have worked in 20 different projects with a total of 28 customers.

While our research focuses on the learning experiences caused by the multidisciplinary aspect in general, we believe that our research findings are beneficial and interesting to computer science and engineering education researchers in particular. This is because computer science is a discipline that nowadays penetrates all the sectors of business and everyday life. This presence of the computing discipline can also be seen in the project topics of the multidisciplinary course under study. Thus, students in computing disciplines can benefit greatly from the experience gained from working in multidisciplinary teams.

\section{Related work}

\subsection{Project-based learning}

The pedagogical approach utilized in this multidisciplinary project is project-based learning. Helle, Tynjälä, and Vesterinen (2006) consider two aspects to be crucial to projectbased learning: projects involve a student-defined solution to a problem, and projects commonly produce some kind of end result, such as a report or design plan. They also emphasize problem orientation as the most distinctive feature of project-based learning. While all project-based learning is essentially problem-based (De Graaff and Kolmos 2003), project-based learning is more authentic, and the deliverables are more concrete and implemented into use (Helle, Tynjälä, and Vesterinen 2006).

\subsection{Multidisciplinarity in project courses}

Computer science and engineering project courses are often monodisciplinary capstone projects, as is evident from a cursory glance at the different literature reviews and other published research analyzing engineering design (Dutson et al. 1997) and computer science projects (Fincher, Petre, and Clark 2001), for example. However, there is also an increasing number of multidisciplinary and interdisciplinary projects. As Morse et al. (2007) point out, interdisciplinary or multidisciplinary are terms that are often used when more than one discipline is involved in teaching or research, but these terms are usually not well-defined. For the sake of simplicity, we will not go into detailed analysis of the usage of these terms, but rather consider them to mean situations in which different disciplines interact. A similar approach is used by Borrego and Newswander (2008), who use the general term cross-disciplinary to refer to both interdisciplinary and multidisciplinary collaboration.

Experts-in-team (Jaccheri and Sindre 2007; Sortland 2004) is a large-scale framework for organizing university-level project courses. Up to 1,500 students are divided into "villages" of 30 students, with each village being assigned its own theme for projects. Students are then divided into 6 teams of 5 students, with the aim that each student in 
the team comes from a different discipline. The theme assigned to each village combines two disciplines, such as Art and IT. Daniels and Asplund (2000) describe a course where students from computer science, electrical engineering, and mechanical engineering work together to build a team of robots for robot soccer world championships. All 90 students work within the same project, and with a clearly defined contribution from each discipline. Ivins (1997) reports on a project course where courses from two different schools are combined to create a multidisciplinary project course with students from the engineering and design disciplines. Kruck and Teer (2009) describe a project course where experienced adult students from business administration and degree students from accounting are brought together for a multidisciplinary course. A combination of existing courses is used in a project course reported by Burnell, Priest, and Durrett (2003), where three different disciplines and universities work together to make the best possible use of the limited resources available and offer product development exercises in multidisciplinary project teams.

Brownell and Jameson (2004) describe a project course where all the students in the project teams are drawn from the same master's program but with different backgrounds, and work on interdisciplinary problems. In a course titled IT in Society (Daniels and Cajander 2010), the students are all from computer science, but the project topics are real-world cases, and multidisciplinarity appears in the areas of application of IT, such as the hospital environment. While most of the above courses are capstone courses aimed at final-year master's students, Hirsch et al. (2001) describe a freshman course where students from both engineering and communication are brought together.

On the basis of our non-systematic review, multidisciplinary or interdisciplinary projects appear to divide into two categories:

- Students from different disciplines work together on a project (cf. Experts-in-team),

- Students from one discipline work within a project that is focused on real-life problems and areas outside their pure discipline (cf. IT in society).

In the present study, multidisciplinarity is present through both of these categories: students work as members of multidisciplinary teams and on real-life open-ended project topics. The specific feature of this course is that we have had students from each of the seven Faculties, and within those from 18 out of 19 departments. This is illustrated in Appendix A, which shows the team compositions by department of the three course instances under study. All teams have had students from at least three different departments when they have started their project work (team number 19 is the exception here due to student drop-outs during the course). The multidisciplinary nature of project topics is illustrated in the following section through project examples.

\subsection{Benefits of multidisciplinarity}

Several examples of the benefits for students working in multidisciplinary teams compared to monodisciplinary teams can be found in the literature. Quantitative analysis conducted by Hotaling et al. (2012) supports their hypothesis that students on a multidisciplinary capstone course have both better job placement and better evaluation of project results compared to students who work in monodisciplinary teams. Students also prefer working in multidisciplinary teams: they consider the project worthwhile, despite unequal distribution of the workload (Mosiman and Hiemcke 2000). Students consider multidisciplinary projects to be more challenging but also more rewarding than monodisciplinary projects, and the importance of the teaming phase can be seen in student feedback (Burnell, Priest, and Durrett 2003). Students see working with people from varying backgrounds as a positive aspect (Kruck and Teer 2009). Ivins (1997) reports 
that despite students' early reactions of fear and anxiety originating from difficulty of the project brief and working with students from different schools, their post-course reflection was mostly on positive outcomes: increased self-confidence and improved problemsolving and decision-making skills. Working in multidisciplinary teams also transformed students' negative and dismissive stereotypes into more positive and realistic views of other disciplines' students. In addition, multidisciplinarity and communication were seen as important parts of the learning process. Students often feel that they learn different things in multidisciplinary project courses compared to normal lecture courses and give positive feedback about these learning experiences (Jaccheri and Sindre 2007), while such positiveness also constantly emerges when students compare monodisciplinary projects with lectures (e.g. Isomöttönen 2011).

\section{Course description}

In this section, we describe the history and motivation behind the project course. We also describe the main features of the course and the preparations needed to organize one instance of the course.

\subsection{Background and history}

The present multidisciplinary working life project was created within a development project funded by the European Social Fund (ESF) and administered by the Agora Center research unit of the University of Jyväskylä. The main goal of the development project was to improve collaboration and knowledge transfer between local small and medium-sized enterprises (SMEs) and the university, an area which was seen as in need of improvement. The resources of SMEs participating in the development project were often rather limited and the scale of their problems were suitable for student course exercises and as thesis topics, and thus it was natural that collaboration focused on utilizing these student resources.

Based on the experiences of the collaboration between SMEs and students gained in the development project, a multidisciplinary project course with real-life customers was piloted during the summer term of 2011. As the course was run without content-oriented input from the faculties no single discipline was the focus and thus a multidisciplinary approach to the course was natural. This meant that the project topics were by and large not limited in any way and hence collaboration became possible with a wide range of customers in different business sectors. Accordingly, the focus of the learning was on general working life skills rather than on enhancing the students' substance skills.

\subsection{Learning goals and grading}

The course sets four learning goals to students. After completing the course, students should:

- Be able to recognize their own expertise and strengths in both project and team work;

- Be able to apply the theoretical knowledge of their discipline and other competencies in a real-world case;

- Be able to work as a responsible member of a project team and work with the customer;

- Know the basic concepts of project work, which include the ability to set goals for a project, write a project plan, realize the project in a multidisciplinary team, and present the results to the peer group. 
All students are individually graded as pass/fail. Pears et al. (2001) have demonstrated that using pass/fail when assessing students is sufficient and does not affect student motivation in a negative way compared to more detailed grading systems. In order to pass the course, students need to actively participate in the project, which means that they have to work at least 120 hours on the project and keep track of their working hours. The documents required by the course are project plan, mid-term report, project report, and personal learning report. At the end of the projects, teams present their results to the customer and to the course coordinators. In the project reports, student teams summarize and analyze project deliverables and how they managed the project, and provide feedback on the course. These requirements can be easily graded as pass/fail, while the working hours tracking enables monitoring of student participation throughout the project. Students have to monitor themselves how the workload is distributed within the team, and thus it is also the teams' internal responsibility to prevent free-riding. Customers give feedback on the projects, which affects how the course is developed and supports student learning, while it does not directly affect whether an individual student will pass the course. Instead of "measuring" whether the students achieve the predetermined learning goals, the focus is in enhancing their learning during the course with a dialogic process in which the course coordinators give feedback on the students' deliverables.

So far all the students who have finished their project work have passed the course. Altogether, 103 students were accepted to the course. Of these, 6 canceled their participation, 5 dropped out during the introductory lectures, and 4 students dropped out during different phases of the project work. Thus 88 of 92 students who started the project also passed the course, which equals to $96 \%$. While a great majority of the students pass the course, they do not consider it to be an easy course. Instead, they have commented the course having extremely heavy workload. Similarly, Brown (2000) reports that students enjoy project work and often spent more hours than required to complete the projects.

From the research point of view, we are not interested in how well students reach the learning goals, nor are we trying to evaluate the course. Instead, we are interested in the conceptual mechanisms that explain the students' learning experiences, as derived from their personal learning reports.

\subsection{Preparations}

Thus far, during the three instances the course has been organized, there have been two course coordinators. Before the course starts, their responsibility is to plan the course schedule, screen prospective customers, and deal with students' applications for admission to the course.

All prospective customers are met face to face to discuss their needs and potential project topics. Customers are informed about the nature of the projects in these discussions. That is, they act strictly as customers, not partners, and participate in project work only by advising and giving feedback and information needed by the students. Eligible customers sign a preliminary agreement to participate. Final project topics are not decided at this stage, but tentative project topics and guidelines are agreed upon. Once the student application deadline has passed, all applications are evaluated and summarized, and student profiles are created on the basis of their free-form applications. Prospective customers and student applicants are then matched to form student teams. This matching has three equally important aspects that need to be satisfied:

- Each student should be in a team where he or she can be a useful member of the group. 
- Each team should be multidisciplinary, with members from at least three different disciplines.

- Each team should have a combination of skills that can enable them to realize the project.

The final selection of customers and students for the course depends on this matching process. There are no fixed criteria for the selection of students or customers, and due to resources there is a limited number of seats for students, which means that some of the prospective customers and students are inevitably left out. As this project course is optional and not a required course in any degree, this does not cause any delays or problems for students regarding their graduation. Interested students are advised to reapply for the next course instance.

\subsection{During the course}

At the beginning of the project, students receive introductory lectures on project work, working with customers, communication, and multidisciplinary teamwork. These lectures are scheduled for the first two or three days of the course, and no other mandatory lectures follow. During the lectures, students meet other team members for the first time, and their teaming phase starts.

Promotion of an authentic working life experience, which is the course target, is mainly implemented by using real customers and open-ended project topics. While the course coordinators have negotiated with customers about the project topics, it is the responsibility of each team to finalize and agree upon the project topic with the customer and write a corresponding project plan. At no point do the course coordinators participate in the meetings between the team and the customer or get involved in fixing the project topic.

There are only four mandatory checkpoints for all teams. First, the course coordinators check and comment on the first version of their project plans with the teams around three weeks after the course has started. A meeting with the project managers takes place around the mid-point of the project, along with a similar meeting for all the students on the course. Teams have to write a project mid-term report after these two meetings. Otherwise, the student teams work independently.

The above-mentioned features that aim to promote an authentic working life experience accords with the "thrown in the deep end" approach: students have to work with previously unknown people for a customer on a project topic that may be outside their core skills, and they have to learn to work independently and take responsibility of their work without constant supervision. This approach of light tutelage and independent work was in fact even more extreme the first time the course was run, but was then moderated somewhat following student feedback: introductory lectures were added and the possibility of tutelage on request was emphasized.

Once the projects are finished, the teams prepare a final presentation for their customer and the course coordinators. In discussions following this presentation, feedback is collected from both customers and students. Customers are also given a feedback form to fill in later on. So far, the project customers have shown a high level of satisfaction with the course arrangements, student teams, and project deliverables.

There is also a final seminar where the teams present their project to the other teams, and the course coordinators sum up the course. Student feedback is collected along with each teams' project report and the individual student learning reports. In their personal learning reports, students are asked to reflect on the project, team work, customer, their own learning experience, and what they consider to be the positive and negative sides 
of the whole project. After the course is finished, each student receives an individual project certificate that can be used, for example, as a reference when applying for a job.

Table 2 summarizes a single course instance described above. One course instance lasts around 15 weeks. A project contract that is signed by the university, customer, and students stipulates that students do not need to spend more than 180 hours on the project. An important part of learning is planning the project so that the goals can be achieved. Students take advantage of computer labs and meeting rooms, while they also work off-campus. In the project plan, they are expected to plan the practice of their collaboration including the timetable.

In the classification of computer science project courses by Fincher, Petre, and Clark (2001), this course best corresponds to the "Project with a client" type of course. However, this definition excludes the multidisciplinary aspect of our course. A brief description that would include all the main aspects of our course could be "Multidisciplinary one-semester course with real customers and open-ended problems." While there are no extensive lectures on the topics that projects involve and students are expected to utilize their existing skills, we do not consider our course to be a "capstone" course. Our course might also be classified as an "Open-ended Group Project" (Daniels and Cajander 2010).

\subsection{Examples of project topics and deliverables}

Examples of the projects realized by multidisciplinary teams during the first three course instances are given below:

- Example 1: Customer was a micro-sized company in tourism and travel business who wanted to increase the number of visitors during their off-season. The student team produced a report on the current state of company's web-based marketing and coverage. They redesigned the company's website, created new content for the website, and created new self-directed activities for tourists.

- Example 2: Customer was a small-sized IT company that was launching a new product and wanted help in their marketing efforts. The students designed a logo, slogan, and visual look, as well as a brochure and website for the product. They also created a prototype version of the product and conducted a customer survey and competitor analysis.

- Example 3: Customer was a micro-sized company that was creating a new web-based service. They wanted to strengthen the brand of the company and receive help on the development of the service. The students designed and created a promotional video of the service, conducted a competitor analysis, and devised a questionnaire for the current and potential users of the service.

These examples illustrate the wide range of projects realized in the course. We have observed that IT is the element often included regardless of the main business domain of the customer. However, the projects of the course are not intended to be system-development projects or requested as such. Student teams are involved in defining the project goals together with their customers, meaning that the students from several disciplines are sharing ideas and innovating solutions together with customers for given open-ended problems. Here, different disciplines such as business and marketing, computer science, and arts and humanities meet. Depending on the project topic, some students in the teams provide technical perspective, while others bring understanding of the customer's business domain or add a human-centered perspective, for example. After the period covered by our research data the spectrum of customers has broadened to cover areas such as culture, sports, learning disabilities, entrepreneurship, and environment. 


\section{Method}

Our research interest was in general to develop an understanding of multidisciplinary student project work. The results of the study bring to the foreground conceptual mechanisms, generally related to multidisciplinarity, which emerged from and explain the students' experiential data. The research method of the study is the grounded theory method originally formulated by Glaser and Strauss (1967). This method was selected due to our interest in the phenomenon of multidisciplinary project work instead of validating the course through hypothesis testing or verifying existing theory. Our main reference to the grounded theory method is the classic form of it (Glaser and Strauss 1967; Glaser 1978, 1992, 2004), which by its definition was deemed suitable for our research interest.

The use of grounded theory method is increasing (van Niekerk and Roode 2009) and has been encouraged (Kinnunen and Simon 2010) within engineering fields. The article by Case and Light (2011) suggests that the use of grounded theory and other "emerging methodologies" can expand the research in engineering education. The classic grounded theory method has been used in ICT-related dissertations by van Niekerk (2009) and Isomöttönen (2011). The study by Gregory and Jones (2009) provides an example of the classic grounded theory study in higher education.

At the beginning of our results, we provide a general description about how multidisciplinarity showed up in our data (cf. content analysis), while the main focus of the paper is in the grounded theory analysis provided thereafter.

\subsection{Grounded theory}

The general idea of the grounded theory is that the process which generates the theory should not be separated from the theory itself. It considers theory a process emphasizing the "generation" of the theory instead of fixed conceptualizations. Accordingly, the grounded theory method is characterized by the tenets such as "ever-developing" and "theory as a process" (Glaser and Strauss 1967, 32). The value of it is in the relevance of theory generated from the data (cf. deductive theories).

The analysis procedure in grounded theory is called the constant comparative method consisting of four stages (Glaser and Strauss 1967):

- Comparing incidents applicable to each category.

- Integrating categories and their properties.

- Delimiting the theory.

- Writing the theory.

These stages are overlapping and done simultaneously as opposed to a linear order. This enables the continuous development of the theory emerging from the data, and the inclusion of new data as the research advances. Grounded theory is iterative by nature, and once a relevant core category or framework begins to emerge, the analyst focuses on the theory development around this core.

In grounded theory "all is data," and instead of worries about data accuracy, the emphasis is placed on the researcher's ability to conceptualize from the data. Theory development is bounded by the current data, and the resultant theories are open to modification. The grounded theory presented in this paper should thus not be seen as a fixed conceptualization.

Section 4.3 shows through examples how the constant comparative method was utilized in this research. A more detailed description of the grounded theory analysis and constant comparative method is provided by Glaser and Strauss (1967, 101-115). 


\subsection{Data}

The data analyzed in this study are the learning reports produced by students at the end of their projects. After the course was held for the third time in summer 2012, all the students who had passed the course were sent a research permit request by email by a course coordinator who is also an author of this research. Altogether, 66 students out of 88 gave permission for their learning reports to be used for the research purposes. We did not receive responses denying the use of answers for research. Regarding those who did not respond, we believe that the email retrospectively requesting the research permit was out of students' interests. It is worth noting that almost 1.5 years had passed from the first course instance, and some students had already graduated.

As we requested the research permission retrospectively, the research did not affect the data used. The data thus realistically reflect students' experiences collected as a natural part of the course close-up activities. It is also worth noting that no direct questions were set for the students to answer in the reports, and that the questions accompanying the assignment were intended to structure their analysis and process of self-reflection. Moreover, we consider data applicable to research in the sense that students seem to express their frustration and problems in the data. It should be noted here that the course is graded only with pass/fail, meaning that students do not have to restrict their criticism of the course in the fear that this would affect their grade. These aspects are in line with the idea that the role of a grounded theorist is essentially a passive one (Glaser 2002).

The report assignment is given during the start-up lectures so that the students are able to prepare for them early on. More detailed instructions on the assignment are given during the final seminar, where the students are shown some previously collected student feedback. The aim is to encourage students to reflect on their experiences instead of writing a list of the tasks they did during the project. Thus a diary type of report is not encouraged, but explicitly forbidden. Students are advised to write the reports so that they too can benefit from them. There is no length requirement, and the report has no effect on the students' grading. These instructions mean that the content and length of the reports vary widely, from half a page up to six pages, and from a few notes about project work to long analyses and self-reflection about everything that happened during the project.

\subsection{Analysis procedure}

We began by open-coding (Glaser 1978, 56) the data with ATLAS.ti software. The first author did the initial open coding by first reading through all the learning reports to obtain a general view of the data, and then by coding all the key points that emerged as interesting. In the data, multidisciplinarity emerged as one of the most meaningful aspects for the students. Following this stage, the second author reviewed the codings related to multidisciplinarity in a shared session, and some re-codings were made. Initial emergent theoretical ideas were written down from the very beginning.

Through sorting out the resultant codes, the analysis continued with attempts to integrate the results into conceptual hypotheses and a coherent theoretical view (see Glaser 1978). Finally, the research process became selective, focusing on the theme of multidisciplinarity, and evolved into an iterative process where after several integrative stages, re-perusal of the data, and writing sessions, the final theoretical framework emerged.

Glaser $(1978,72-82)$ has proposed several coding families that can facilitate the integration of theory. In our case, we find the resultant theory to resemble a 'typology' (Glaser 1978, 65-68) within which several 'causalities' (Glaser 1978, 74) can be identified. We refer to these causalities as mechanisms. 
In grounded theory, "categories and properties are concepts indicated by the data": a category is a conceptual element of the theory, and a property is a conceptual aspect or element of a category (Glaser and Strauss 1967, 36). A key feature of a grounded theory is the emergent core category, which ties the theory together and is meaningful for those involved. The core category of the present grounded theory is seen as a kind of contingency, signifying what happens when students encounter multidisciplinary project work. Thus there is no single mechanism in play when the students, with their various motives and attitudes, arrive to start the course; instead, their learning experiences can vary, resulting in both positive and negative experiences, and possible transformations from negative to positive experiences. Within this framework, there are opportunities for valuable learning experiences, in particular through the identification of the peculiarities of one's own discipline and expertise - as will be explained in the Results section.

The key element of the grounded theory analysis is how conceptualizations emerge from comparison (Glaser and Strauss 1967, 101-115; Glaser 1978, 62). An example is given as follows: at certain point of coding, we had a category 'Working outside comfort zone,' which refers to situations where students face tasks outside their expertise. In our data, students reflected this situation as being frustrating, and thus Frustration became one property characterizing this category. Through comparing on-coming data incidents with this conceptual scheme, we observed that some students' response to this same situation was more mature and favorable. Thus, Maturity became another property of the same category. Further comparing these two conceptualizations, we noted that Maturity was always preceded by Frustration instead of being a direct consequence of working outside comfort zone, and noted that transformation from Frustration to Maturity occurred in some cases. Continuing the comparison, team spirit emerged as a factor in whether this transformation occurred, and transformation became a category with team spirit as its property.

\section{Results}

This section presents the results of our analysis. We begin by describing the general view that students had of the course and multidisciplinarity, and then continue by focusing on the mechanisms that reveal how multidisciplinarity played a role in learning.

\subsection{General experience of the course and multidisciplinarity}

In the 66 learning diaries, we found a total of 112 comments on multidisciplinarity. These were either direct comments or descriptions of situations that we interpreted as relating to multidisciplinarity. More specifically, these 112 comments were found in 48 different learning diaries, which means that $73 \%$ of the students commented on multidisciplinarity in some way. The richness of information in what we refer to as a single comment varied greatly. One code about multidisciplinarity could originate from several paragraphs across the report or be an explicit expression about multidisciplinarity.

While some negative and neutral comments were found, overall the course feedback was mostly positive:

[student:] It was a long journey, sometimes very stressful but really rewarding and it was worth it.

[student:] If I had known how much work the course required I might not have applied. But I am happy I did, this was absolutely one of the best courses in my university studies.

Comments of this kind are in agreement with the literature on student project courses, 
where positive experiences are often found even if a lot of problems have been experienced during the course. This can be attributed to the fact that these projects are often students' first experiences of more practical coursework after their theoretical courses, boosting their positive experiences (Isomöttönen 2011). Most of the students commented on the multidisciplinarity of the course in either a positive or neutral way:

[student:] Multidisciplinarity was clearly a benefit in this project since the project required a lot of different skills.

[student:] I think our group's strength was that our disciplines were so different and everybody brought their own expertise to the project.

[student:] I felt that multidisciplinarity was neither a benefit nor a handicap.

In fact, we found no directly negative comments, and most of those who saw multidisciplinary teams as a challenge commented that such a setting was rewarding:

[student:] Now I know how challenging it is to form a well-working project team, but I also know how rewarding it is to work in a project where different skills [refers to different background of team members] and personalities meet.

On the basis of these generally positive responses, we are inclined to conclude that, from the student perspective, this practical and multidisciplinary course is a worthwhile addition to the curricula of many faculties.

\subsection{Overview of the effects of multidisciplinarity on learning}

Figure 1 summarizes the grounded theory that emerged on the effect of multidisciplinarity on learning experiences, as interpreted from the students' experiential reports. The main concepts that we were able to identify settled on the matrix with two orthogonal axes. The horizontal axis describes whether the learning experience was negative or positive, and the vertical axis whether it was caused by the multidisciplinary project topic or multidisciplinary team. Those student experiences that were identified as being caused by working with a project topic outside their expertise were grouped into the Multidisciplinary project topic, and experiences caused by working with people from different disciplines were grouped into the Multidisciplinary team.

We found the multidisciplinary project topic to be related to three main categories; 'Working outside comfort zone,' 'Gaining a perspective on core skills,' and 'Recognizing lack of expertise,' the last of which follows from the first mentioned (see Figure 1). Further, we identified four different concepts that relate to the main categories as their consequences: 'Contentment,' 'Maturity,' 'Frustration,' and 'Uncertainty.' Both positive and negative experiences followed from 'Working outside comfort zone,' while the two other main categories were linked with purely positive or negative experiences.

The multidisciplinary team was found to be related to two main categories, 'Recognizing expertise' and 'Gaining a perspective on general skills.' Three concepts, 'Frustration,' 'Maturity,' and 'Increased occupational identity,' were found to be linked to these categories as consequences.

We thus found that multidisciplinarity plays a role in student learning experiences in several ways: the theory in Figure 1 captures several different conceptual mechanisms. Further, we also identified transformation in the consequences of multidisciplinarity from negative to positive, meaning that the learning experiences arising from particular factors are not always fixed and thus that there is no right way to learn or teach on this course. In this sense, we associate the generated grounded theory in Figure 1 with the "contingency theory,' along the same lines as Gregory and Jones (2009).

In the following sections, we review the mechanisms found in Figure 1. We begin with 


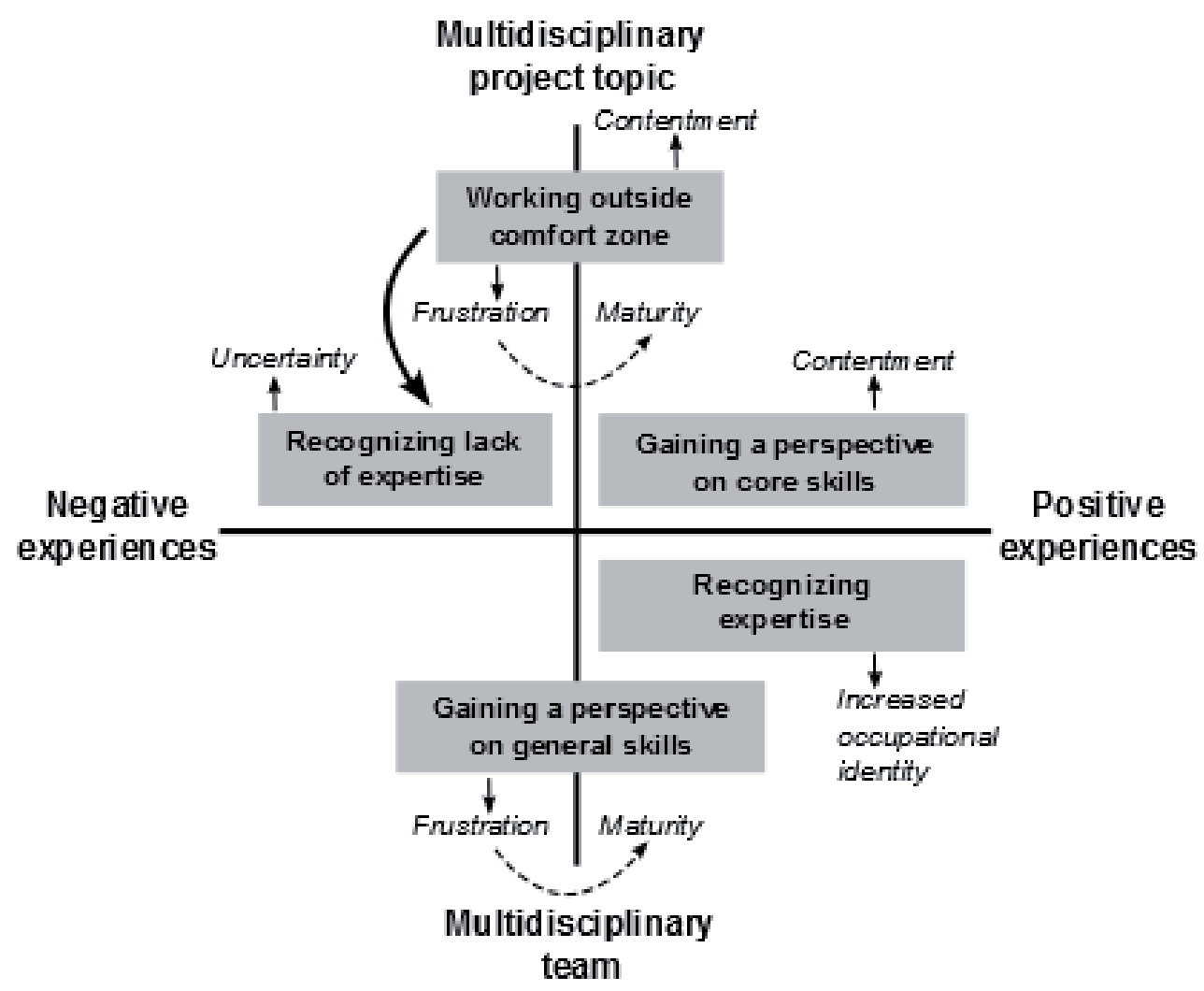

Figure 1. Learning mechanisms in Multidisciplinary project work

the mechanisms that relate to the multidisciplinary team and continue with those that relate to the multidisciplinary project topic.

\subsection{Multidisciplinary team and learning}

Mechanism: Recognizing expertise $\Rightarrow$ Increased occupational identity

'Recognizing expertise' refers to the situation where students start to understand their own discipline, i.e., what they have actually learned during their university studies and what possibilities they have to utilize these skills. This occurs when students are put to work in a multidisciplinary team and start to compare themselves to the others in the team. This causes positive feelings and self-confidence and increases students' occupational identity, as illustrated by the following quote:

[student:] I have sometimes wondered what the gain from my own discipline to my subsequent working life could possibly be, but then I noticed that during the project that I often relied on my sociological imagination and the methods I had learned during my studies. It is a really great feeling to be able to utilize them in a real and meaningful way.

The effect of being a part of multidisciplinary team was particularly emphasized when students made favorable comparisons to their previous experiences of monodisciplinary teamwork:

[student:] Because the team was multidisciplinary I realized that I actually know quite a lot about human behavior and the factors affecting it. When talking to other students with the same major this was not so evident but when I was working in this team I noticed that lots of the things that are obvious to me are new to others. 
In our opinion, this self-discovery of "Who $I$ am" is the one of the most important learning experiences that emerged from data.

\section{Mechanism: Gaining a perspective on general skills $\Rightarrow$ Frustration $\Rightarrow$ Maturity}

'Gaining a perspective on general skills' occurs when students possess a set of general skills that they have used before in monodisciplinary teamwork or in some other setting. They have some understanding of these skills and how well they are able to use them. When put to work in a multidisciplinary team, they are faced with a new situation, and hence see their skills in a new way. They do not necessarily learn new skills but better understand their existing skills and how these skills can be utilized:

[student:] It was interesting from the viewpoint of teamwork skills to work with students from different disciplines because teamwork was different compared to working with students from my own discipline. With them the working style is quite similar but in the multidisciplinary working life project I learned how others work and also to modify my own working style to suit different situations.

While students find 'Gaining a perspective on general skills' for the most part a positive thing, it can also be a source of negativity, in particular frustration, during project work. For some students, this frustration transforms into maturity as the project advances and the students begin to understand other students' characteristics and ways of working:

[student:] There were a lot of different kinds of personalities in the team. In teamwork in my own discipline the people are more homogeneous. Even though there are different personalities there as well the background is more or less the same... I learned to cope better with team members' whining and to sift the essential parts out from the daydreamers' great visions and in the future I will have at least a little bit more courage to give my own opinions.

\subsection{The multidisciplinary project topic and learning}

\section{Mechanism: Working outside comfort zone $\Rightarrow$ Frustration $\Rightarrow$ Maturity}

Situations inevitably arise in this course where students are faced with real-world project topics that do not allow them to fully utilize their core skills. Because the students come from different disciplines, the project topics appear multidisciplinary, and hence may require them to operate outside their comfort zone to be able to contribute to the project. They then have to start learning requisite skills alone or with another team member; it is this situation that we refer to as 'Working outside comfort zone.'

Working outside comfort zone implies a learning mechanism that starts from feelings of frustration that gradually transform into maturity. This frustration can hinder teamwork, and, when it turns into maturity, may give rise on reflection to feelings of embarrassment:

[student:] It was from these situations outside my comfort zone [a student of humanities was designing a web site] that I learned the most about myself. I have a lot to improve in my teamwork. I have always considered myself a solidary team player but now I noticed myself whining to other team members just like a teenager. I am embarrassed by my behavior but I have decided to learn from this experience.

A quote from another student in a similar situation shows that this transformation can happen when the students see the project advance and they can contribute to it in a meaningful way. Team spirit can also serve as an enabling element in this transformation:

[student:] When the project progressed and the results started to seem more concrete my own motivation also started to grow. I believe this was because the project tasks progressed 
and that I noticed I can manage them even though I was very uncertain in the beginning. Another even bigger factor was our team spirit which grew stronger during the project.

Viewing this situation from another angle, students who possess the requisite skills and are working within their comfort zone might feel disappointment and frustration. For them, the other students are a burden, and they feel that they have to do all the work themselves:

[student:] I was slightly disappointed after the first few meetings when I realized that three of the team members did not possess the skills to contribute to it or were not interested in the business-related part.

As a side note, this team finalized their project successfully, and the customer was satisfied with the results. However, the team spirit in this particular team turned out to be poor, and negativity and accusations directed at other team members appeared in their learning reports. It seems that team spirit can play an important role in students' learning processes, especially in whether the students can transform negative experiences into positive ones during the project.

It is also worth noting that one team decided early on in the project that nobody needed to work on tasks they were not familiar with. While this may be an efficient way of working, it eliminates the possibilities for the above-mentioned learning experiences caused by 'Working outside comfort zone'.

\section{Mechanism: Working outside comfort zone $\Rightarrow$ Contentment}

Furthermore, students who worked outside their comfort zone reported learning new skills. The students in this situation were able to practice new skills and learn the terminology and basic concepts used in other disciplines. This leads to positive learning experiences, which we refer to as 'Contentment':

[student:] Business process modeling was a completely new thing for me. Now I love it [...] and $I$ am going to apply it in the future in several areas.

In particular, Contentment emerges when students have a positive general attitude towards practicing and learning new skills. In other words, practicing new skills is seen as an opportunity rather than a challenge:

[student:] My personal goal in joining the course was to learn something new and practical for working life. Making brochures, creating the website and meetings with the customers were in my opinion the most important parts of the project in regards to achieving that goal.

\section{Mechanism: Working outside comfort zone $\Rightarrow$ Recognizing lack of expertise $\Rightarrow$ Uncertainty}

Working outside one's comfort zone can cause students to compare their skills with the project's requirements in a negative way. They start to question their own competence and role in the project and notice that they do not possess the skills required. We refer to this as 'Recognizing lack of expertise':

[student:] I was concerned about my part in the project since I have no knowledge at all of marketing or sales.

This comparison causes 'Uncertainty' among the students:

[student:] I started to doubt my own competence with regard to the tasks I was assigned, and I was worried by the somewhat large amount of time that the entire course required. 
We can contrast this learning experience with 'Recognizing expertise' through working in a multidisciplinary team. We did not find any comments to the effect that working in a multidisciplinary team or with unknown people caused uncertainty of this kind.

\section{Mechanism: Gaining a perspective on core skills $\Rightarrow$ Contentment}

Due to the presence of a real customer and a multidisciplinary project topic, some students were able to draw on and combine several of their core skills. We refer to this as 'Gaining a perspective on core skills.'

[student:] I was able to utilize my previous experience of creating websites as well as my expertise in environmental and ethical issues and combine all these things in a way I had not done before. This was a good experience that suited me well.

Here, 'Contentment' is also a consequence of learning. Thus, the learning mechanisms in this case resemble that mentioned above, where 'Contentment' emerged from working outside one's comfort zone.

\section{Conclusions and discussion}

In this article, we analyzed the learning experiences of students enrolled in a multidisciplinary project course. The students' attitude towards the multidisciplinarity of the course, present in the multidisciplinary nature of the project topics and working with students from other disciplines, seems to be positive overall.

The main contribution of this study is a unified theoretical picture that captures the mechanisms that explain the student experiences of a multidisciplinary course setting; see Figure 1. We consider two mechanisms the most important ones. First, working in a multidisciplinary team enables students to recognize the peculiarities of their own discipline, and thus their own expertise, which increases their sense of occupational identity. Second, engagement in a multidisciplinary project topic directs students to work outside their comfort zone. Reactions to this situation differ among students. For some of them it is an experience that results in contentment. For others it can cause frustration, which again can transform into maturity as students come to realize that they can make progress. A supportive team spirit can contribute to this transformation.

Students' positive attitude towards multidisciplinary project courses has been reported by several authors (Burnell, Priest, and Durrett 2003; Ivins 1997; Jaccheri and Sindre 2007). Ivins (1997) noticed that working in multidisciplinary teams enabled students to break somewhat negative prejudice that they potentially have against other disciplines' students, which is complemented by our findings on the occupational identity. While researching computer science projects, Isomöttönen (2011) noticed that one and the same element in a realistic project course can engender both a positive and negative experience, and attributed this to the fact that several issues in project-based learning are of sensitive nature - this is likely to relate to our concerns about how the transformation from frustration to maturity can occur. Our findings also support the notion of Gregory and Jones (2009) "that there is no one best way of teaching" in a sense that both team composition and project topic have different and non-fixed effects on learning experiences.

We have not come across grounded theory studies on multidisciplinary student projects; one grounded grounded theory analysis has been applied to multidisciplinary research teams in academia (Younglove-Webb et al. 1999). In this connection, the emergent theoretical framework in Figure 1 can be utilized in planning a multidisciplinary project course, evaluating such a course, or informing research surveys about student learning in a multidisciplinary context. For instance, a teacher of a multidisciplinary project 
course can be interested in promoting a certain learning experience, such as Recognizing expertise, and focus the course planning accordingly, in this case by emphasizing the multidisciplinarity of student teams. In general, the value is that using this substantive theory teachers can "work with familiar occasions purposefully" (Glaser 1978, 14).

The grounded theory method allows the constant development of theory. Thus we can continue our research and take into account such factors as hours spent on the project, students' major and other background information, project topic, and the team spirit. This can be done by analyzing further the data we have already obtained. This includes students' learning reports, projects' final reports, and the working hours students have reported. Utilizing this data would allow us to deepen the theoretical framework in Figure 1. For example, the hours spent by each student could provide interesting insights into learning experiences. We have also planned doing a full content analysis on the students' learning reports to develop a complete picture of the course and aspects other than multidisciplinarity.

Using projects in computer science education has a long history (Tomayko 1998), with a range of recognized project-based course models (Fincher, Petre, and Clark 2001; Clear et al. 2001). In our view, multidisciplinary project work can revitalize computer science projects with one prominent benefit being the emerging possibility of identifying the peculiarities of one's own discipline. From a more practical viewpoint, it would be necessary to investigate more profoundly how the transformation from frustration to maturity, as discussed above, occurs, and how this process could be enhanced - in order to emphasize positive learning experiences.

\section{References}

Borrego, Maura, and Lynita K. Newswander. 2008. "Characteristics of Successful Crossdisciplinary Engineering Education Collaborations." Journal of Engineering Education 97 (2): $123-134$.

Brown, J. 2000. "Bloodshot eyes: workload issues in computer science project courses." In Proceedings of Seventh Asia-Pacific Software Engineering Conference, 2000, 46-52.

Brownell, Judi, and Daphne A. Jameson. 2004. "Problem-Based Learning in Graduate Management Education: An Integrative Model and Interdisciplinary Application." Journal of Management Education 28 (5): 558-577.

Burnell, Lisa J., John W. Priest, and John R. Durrett. 2003. "Assessment of a resource limited process for multidisciplinary projects." SIGCSE Bull. 35 (4): 68-71.

Case, Jennifer M., and Gregory Light. 2011. "Emerging Research Methodologies in Engineering Education Research." Journal of Engineering Education 100 (1): 186-210.

Clear, Tony, Michael Goldweber, Frank H. Young, Paul M. Leidig, and Kirk Scott. 2001. "Resources for instructors of capstone courses in computing." SIGCSE Bull. 33 (4): 93-113.

Daniels, Mats, and Lars Asplund. 2000. "Multi-level project work; a study in collaboration." In 30th Annual Frontiers in Education Conference, 2000. FIE 2000, Vol. 2F4C/11 -F4C/13.

Daniels, Mats, and Åsa Cajander. 2010. "Constructive controversy as a way to create "true collaboration" in an open ended group project setting." In Proceedings of the Twelfth Australasian Conference on Computing Education - Volume 103, Brisbane, Australia. ACE '10. 73-78. Darlinghurst, Australia, Australia: Australian Computer Society, Inc.

De Graaff, Erik, and Anette Kolmos. 2003. "Characteristics of Problem-Based Learning." International Journal of Engineering Education 19 (5): 657-662.

Dutson, Alan J., Robert H. Todd, Spencer P. Magleby, and Carl D. Sorensen. 1997. "A Review of Literature on Teaching Engineering Design Through Project-Oriented Capstone Courses." Journal of Engineering Education 86 (1): 17-28.

Fincher, Sally, Marian Petre, and Martyn Clark, eds . 2001. Computer science project work: principles and pragmatics. London, UK: Springer-Verlag. 
Glaser, Barney G. 1978. Theoretical Sensitivity: Advances in the Methodology of Grounded Theory. San Francisco, CA: Sociology Press.

Glaser, Barney G. 1992. Emergence vs. Forcing: Basics of Grounded Theory Analysis. Mill Valley, USA: Sociology Press.

Glaser, Barney G. 2002. "Constructivist Grounded Theory?." Forum: Qualitative Social Research $3(3)$.

Glaser, Barney G. 2004. "Remodeling Grounded Theory." Forum Qualitative Sozialforschung / Forum: Qualitative Social Research [On-line Journal] 5 (2). With the assistance of Judith Holton.

Glaser, Barney G., and Anselm L. Strauss. 1967. The Discovery of Grounded Theory: Strategies for Qualitative Research. New York, NY: Aldine de Gruyter.

Gregory, Janet, and Robert Jones. 2009. "Maintaining competence": a grounded theory typology of approaches to teaching in higher education." Higher Education 57 (6): 769-785.

Helle, Laura, Päivi Tynjälä, and Erkki Olkinuora. 2006. "Project-Based Learning in PostSecondary Education: Theory, Practice and Rubber Sling Shots." Higher Education 51 (2): pp. 287-314.

Helle, Laura, Päivi Tynjälä, and Pirkko Vesterinen. 2006. Work-Related Project as a Learning Environment. Advances in Learning and Instruction Series. Amsterdam: Elsevier.

Hirsch, Penny L., Barbara L. Shwom, Charles Yarnoff, John C. Anderson, David M. Kelso, Gregory B. Olson, and J. Edward Colgate. 2001. "Engineering Design and Communication: The Case for Interdisciplinary Collaboration." International Journal of Engineering Education 17 (4 and 5): 342-348.

Hotaling, Nathan, Barbara Burks Fasse, Lewis F. Bost, Christopher D. Hermann, and Craig R. Forest. 2012. "A Quantitative Analysis of the Effects of a Multidisciplinary Engineering Capstone Design Course." Journal of Engineering Education 101 (4): 630-656.

Isomöttönen, Ville. 2011. "Theorizing a One-Semester Real Customer Student Software Project Course." In Jyväskylä Studies in Computing, Vol. 140University of Jyväskylä. PhD Thesis.

Ivins, J.R. 1997. "Interdisciplinary project work: practice makes perfect?." Education, IEEE Transactions on 40 (3): $179-183$.

Jaccheri, L., and G. Sindre. 2007. "Software Engineering Students meet Interdisciplinary Project work and Art." In Proceedings of 11th International Conference on Information Visualization, 2007, 925 -934. july.

Kinnunen, Päivi, and Beth Simon. 2010. "Building Theory About Computing Education Phenomena: A Discussion of Grounded Theory." In Proceedings of the 10th Koli Calling International Conference on Computing Education Research, Koli, Finland. Koli Calling '10. 37-42. New York, NY, USA: ACM.

Kruck, S.E., and Faye P. Teer. 2009. "Interdisciplinary Student Teams Project: A Case Study." Journal of Information Systems Education 20 (3).

Last, Mary Z., Mats Daniels, Vicki L. Almstrum, Carl Erickson, and Bruce Klein. 2000. "An international student/faculty collaboration: the Runestone project." In Proceedings of the 5th annual SIGCSE/SIGCUE ITiCSE conference on Innovation and technology in computer science education, Helsinki, Finland. ITiCSE '00. 128-131. New York, NY, USA: ACM.

Morse, Wayde Cameron, Max Nielsen-Pincus, Jo Ellen Force, and J. D. Wulfhorst. 2007. "Bridges and Barriers to Developing and Conducting Interdisciplinary Graduate-Student Team Research." Ecology and Society 12 (2).

Mosiman, Steve, and Christoph Hiemcke. 2000. "Interdisciplinary capstone group project: designing autonomous race vehicles." SIGCSE Bull. 32 (1): 270-274.

Pears, A., and M. Daniels. 2010. "Developing global teamwork skills: The Runestone project." In Education Engineering (EDUCON), 2010 IEEE, 1051-1056.

Pears, A, M. Daniels, A Berglund, and C. Erickson. 2001. "Student evaluation in an international collaborative project course." In Applications and the Internet Workshops, 2001. Proceedings. 2001 Symposium on, 74-79.

Sortland, Bjørn. 2004. "Experts-in-team - Multidisciplinary project." In Proceedings of UNIQUAL, The 2nd International Conference on Universities' Quality Development, 7B3-8 7B3-13.

Tomayko, James E. 1998. "Forging a discipline: An outline history of software engineering edu- 
cation." Annals of Software Engineering 6 (1-4): 3-18.

van Niekerk, Johanna Cornelia. 2009. "Cost and Reward as Motivating Factors in Distributed Collaborative Learning Assignments: A Grounded Theory Analysis." Ph.D. thesis. School of Information and Communication Technology of The Nelson Mandela Metropolitan University. van Niekerk, Johanna C., and J. D. Roode. 2009. "Glaserian and Straussian Grounded Theory: Similar or Completely Different?." In Proceedings of the 2009 Annual Research Conference of the South African Institute of Computer Scientists and Information Technologists, Vanderbijlpark, Emfuleni, South Africa. SAICSIT '09. 96-103. New York, NY, USA: ACM.

Younglove-Webb, Julie, Barbara Gray, Charles William Abdalla, and Amy Purvis Thurow. 1999.

"The Dynamics of Multidisciplinary Research Teams in Academia." The Review of Higher Education 22 (4): 425-440. 
Table A1. Composition of student teams by Departments

\begin{tabular}{|c|c|}
\hline Team & \\
\hline 1 & $\begin{array}{l}\text { Chemistry; Computer Science and Information Systems; Mathematics } \\
\text { and Statistics; Social Sciences and Philosophy }\end{array}$ \\
\hline 2 & $\begin{array}{l}\text { Biological and Environmental Science; Computer Science and Informa- } \\
\text { tion Systems; Physics; Social Sciences and Philosophy }\end{array}$ \\
\hline 3 & $\begin{array}{l}\text { Computer Science and Information Systems; Health Sciences; Mathe- } \\
\text { matical Information Technology; Social Sciences and Philosophy }\end{array}$ \\
\hline 4 & $\begin{array}{l}\text { Communication; Computer Science and Information Systems; Mathe- } \\
\text { matics and Statistics }\end{array}$ \\
\hline 5 & $\begin{array}{l}\text { Computer Science and Information Systems; Social Sciences and Philos- } \\
\text { ophy }\end{array}$ \\
\hline 6 & $\begin{array}{l}\text { Computer Science and Information Systems; Music, School of Business } \\
\text { and Economics; Social Sciences and Philosophy }\end{array}$ \\
\hline 7 & Computer Science and Information Systems; Languages; Physics \\
\hline 8 & $\begin{array}{l}\text { Computer Science and Information Systems; History and Ethnology; } \\
\text { Languages; Physics; Social Sciences and Philosophy }\end{array}$ \\
\hline 9 & $\begin{array}{l}\text { Communication; Health Sciences; School of Business and Economics; } \\
\text { Social Sciences and Philosophy }\end{array}$ \\
\hline 10 & $\begin{array}{l}\text { Education; Health Sciences; Languages; School of Business and Eco- } \\
\text { nomics; Social Sciences and Philosophy }\end{array}$ \\
\hline 11 & $\begin{array}{l}\text { Art and Culture Studies; Biology of Physical Activity; Computer Science } \\
\text { and Information Systems; School of Business and Economics }\end{array}$ \\
\hline 12 & $\begin{array}{l}\text { Communication; Education; Health Sciences; School of Business and } \\
\text { Economics }\end{array}$ \\
\hline 13 & $\begin{array}{l}\text { Computer Science and Information Systems; Languages; School of Busi- } \\
\text { ness and Economics; Social Sciences and Philosophy }\end{array}$ \\
\hline 14 & $\begin{array}{l}\text { Computer Science and Information Systems; Mathematics and Statis- } \\
\text { tics; Psychology, Sport Sciences }\end{array}$ \\
\hline 15 & $\begin{array}{l}\text { Communication; Computer Science and Information Systems; Educa- } \\
\text { tion; School of Business and Economics }\end{array}$ \\
\hline 16 & $\begin{array}{l}\text { Biology of Physical Activity; Computer Science and Information Sys- } \\
\text { tems; Languages; School of Business and Economics }\end{array}$ \\
\hline 17 & $\begin{array}{l}\text { Computer Science and Information Systems; History and Ethnology; } \\
\text { Mathematical Information Technology; Physics; Social Sciences and Phi- } \\
\text { losophy }\end{array}$ \\
\hline 18 & Education; Languages; Mathematical Information Technology \\
\hline 19 & Mathematical Information Technology; Social Sciences and Philosophy \\
\hline 20 & $\begin{array}{l}\text { Communication; Computer Science and Information Systems; Educa- } \\
\text { tion; Social Sciences and Philosophy; Sport Sciences }\end{array}$ \\
\hline
\end{tabular}


Table 2. Overview of the course structure

\begin{tabular}{|l|l|l|}
\hline When & Who & What \\
\hline Week 1 & Coordinators, Students & $\begin{array}{l}\text { Introductory lectures about } \\
\text { project work }\end{array}$ \\
\hline Week 2 & Coordinators, Students & $\begin{array}{l}\text { Presentation of Customer and } \\
\text { tentative project topic }\end{array}$ \\
\hline Week 2 & Students, Customers & $\begin{array}{l}\text { Negotiations about project } \\
\text { topic }\end{array}$ \\
\hline Week 3 & Students & Start working on project plan \\
\hline Week 4 & Coordinators, Students & Feedback about project plan \\
\hline Week 5 & Customer, Students & Signing the final project plan \\
\hline Week 7 & Students & Project work begins \\
\hline Week 8 & Coordinators, Students & $\begin{array}{l}\text { Meeting with project man- } \\
\text { agers }\end{array}$ \\
\hline Week 9 & Coordinators, Students & Meeting with all teams \\
\hline Week 14-15 & Students & Project mid-term report \\
\hline Week 15 & Coordinators, Students, & Final presentation \\
\hline After the project & Coordinators, Students & Final seminar \\
\hline
\end{tabular}

